\title{
Effective Advertising and its Influence on Consumer Buying Behavior
}

\author{
${ }^{*}$ Ghulam Shabbir Khan Niazi1 ${ }^{1}$ Javaria Siddiqui2, Burhan Ali Shah1, Ahmed Imran Hunjra ${ }^{3}$ \\ ${ }^{1}$ Quaid-i-Azam School of Management Sciences, Quaid-i-Azam University Islamabad, Pakistan \\ ${ }^{2}$ Federal Urdu University of Arts, Science, \& Technology Islamabad, Pakistan \\ ${ }^{3}$ Iqra University Islamabad, Pakistan \\ *gskniazi@yahoo.com
}

\begin{abstract}
Advertising is a way of communication to convince an audience for taking purchase decision about a product or service and delivering information to viewers. This paper examines the relationship between environmental response and emotional response which are independent variables with dependent variable i.e. consumer buying behavior. This research investigates the relationship between the variables involved, by taking the 200 responses in twins' cities of Pakistan. Findings of this study show the moderate relationship between independent variables and dependent variable. It shows that consumer purchase those brands from which they are emotionally attached. This study reports new results in the field of buying behavior of consumers' response.
\end{abstract}

\section{Keywords: Environmental response, Emotional response, Consumer buying behavior}

\section{Introduction}

Of all marketing weapons, advertising has leading impact on viewers mind, as its exposure is much more (Katke, 2007). Marketing mix has four subsets i.e. product, price, place and promotion and advertising is a component of promotional mix, which is used to create awareness about product and services for taking purchase decisions. Marketers use these types of tool for communication purpose. Advertisement evolves date back in the ancient times. Different societies used different types of symbols for the promotion of the products and services for attracting consumers. However, these pictures were used for a limited area for promotion. In modern time, advertisement has become important way to promote products and services and is used for communication purpose. No company can become a market leader unless they invest lots of their investment in promotional purposes (Hussainy et al., 2008). The major aim of advertising is to impact on buying behavior; however, this impact about brand is changed or strengthened frequently people's memories. Memories about the brand consist of those associations that are related to brand name in consumer mind. These brand cognitions influence consideration, evaluation, and finally purchases (Romaniuk \& Sharp, 2004). Most companies do analysis of consumer behavior. The major objective of consumer behavior analysis is to determine the factors that consumers behave in particular circumstances like in economics aspect (Ayanwale et al., 2005). Consumer behavior analysis is helpful for advertiser to understand the behavior of consumer in buying different situations. According to traditional hierarchy-of-effects models, advertising affect of advertising exposure leads to brand cognition and cognition about the ad, which then leads to the attitude towards the ad and the brand until their purchase intent (Mendelson \& Bolls, 2002).

As the market is surplus with several products or services, most companies make similar functional claim; so, it has become extremely difficult for companies to differentiate their products or services based on functional attributes. Differentiates based on functional attributes which are shown in advertisement are never long lasting as the competitors could copy the same (Hussainy et al., 2008). Therefore, the marketers give the concept of brand image. By introducing, the character of caring mother in ads through this marketer creates emotion in the mind of consumers (Jalees, 2006). Doing so advertiser creates those types of ads, which carry emotional bond with consumer. Therefore, that consumer is more likely to associate with ads of those brands, which have emotional values and messages. Today environment without advertising, marketers cannot deliver any information or message about their product or services to their viewers or buyers. In order to analyze this consumer buying behavior through advertisement, we have selected areas of twin cities of Pakistan to conduct our research. This research is based on attitudinal behavior of consumer in different 
buying behavior. Advertisement is a promotional tool that is available for marketers to create awareness about the brand and mould their customers' behavior towards that brand for taking final purchase decision. The major aim of advertiser is to reach potential customers and creates impact on their buying behavior (Ayanwale et al., 2005 and Adelaar et al., 2003). Ayanwale et al. (2005) conducted research on advertisement of Bournvita. As advertising has a major influence on consumers of Bournvita food drink. Similar researches have already been conducted for the quality of Bournvita. Majority of consumer liked Bournvita food drink and this brand has an extended lifecycle in the food drink industry because company invests more in their advertising. Adelaar et al. (2003) conducted study on online compact discs (CDs) shopping behavior of consumer through emotional advertising.

This paper is interested to find out the attitudinal buying behavior of consumer in twin cites of Pakistan, and determine the relationship between emotional response \& environmental response with dependent variable i.e. consumer buying behavior. In the context of local scenario, the practices of advertisements are not mature as compare to developed countries. The advertising institutions are not working as per the market of local scenario and it is very important to select the celebrities to advertise any product. So, in Pakistan there is need to conduct research on advertisement and it affect on consumer buying behavior. This study defines media, which provides information that is represented by the combination of sound, sight, and touch sources. This study covers various areas of the video messages that are presented in media through which people take information. The verbal and visual information affects individual's perception of the environmental stimuli. The result of this study will add new information and knowledge in the existing knowledge and provides new areas for future researchers. This paper is based on theoretical model, which is used to examine the relationship between variables. Hypotheses are developed for applying tests. Then results, discussion and conclusion are presented. At the end, limitations of the study are listed. The basic objective of this research is to examine the influence of emotional advertising through attitudinal buying behavior consumer and further to determine the influence of environmental advertising through attitudinal buying behavior consumer.

\section{Literature Review}

Advertising is a non-personal paid form where ideas, concepts, products or services, and information, are promoted through media (visual, verbal, and text) by an identified sponsor to persuade or influence behavior (Ayanwale et al., 2005 and Bovee, et al. 1995).

Emotional Response: Advertising is to create understanding, liking, and selection of product or services. The most influencing theory in marketing and advertising research is attitude-towards-the-ad. However, the attitude that is formed towards the ad help in influencing consumer's attitudes toward the brand until their purchase intent (Goldsmith \& Lafferty, 2002). Consumer buying behavior is based on the concept and idea that he/she simply decided to purchase a product or service at the spot (Adelaar et al., 2003). The major aim of advertising is to create positive attitude towards the ad and the brand until consumer purchases that product and through this positive attitude create emotional response in the mind of consumer (Goldsmith \& Lafferty, 2002). That is why basic aim of advertising to encourage people to buy things and creates awareness (Bijmolt et al., 1998). According to the traditional attitude theory consumer, behavior is predicted from consumer attitude when consumers buy the brand, which they like the most. An attitude may be defined as "acquire behavioral disposition" (Smith \& Swinyard, 1983). However Adelaar et al. (2003) explained that behavior is produced by emotional response, which is created by three factors:

- Pleasure: the state in which person feel good, happy, or joyful in a particular situation.

- Arousal: the state of feeling that is varying from person to person in different situations i.e. feeling of excitement, active, bored, or sleepy.

- Dominance: this defines individual feelings, which are in control of or free to act in a particular situation.

When consumer watches an advertisement about the brand and develops likeness for the brand and then eventually willing to purchase it (Goldsmith \& Lafferty, 2002). The terminology for 'actual buying behavior' is that consumer in real sense purchase the product or services (Adelaar et al., 2003). The objective of consumer buying behavior is to determine the factor that influence consumer to act in a particular way but in different situation (Ayanwale et al., 2005). Another component of effective advertisement that creates emotional 
response is the consumer ability to recall the brand ad (Goldsmith \& Lafferty, 2002). Thus, the relative importance of brand recall will depend on the extent to which consumer makes product related decisions, which leads to the brand awareness (Keller, 2006). This brand awareness helps in ensuring the recall ad, which has the competitive advantage over those brands that are not recalled easily. Thus positive attitude towards ads have more ability to recall the ads then those having negative attitude (Goldsmith \& Lafferty, 2002). Brand knowledge through advertisement helps in influencing brand salience in an away that the quantity and sparkle of the memories about the brand thought to be in buying situation that creates emotional response towards ads (Holden \& Lutz, 1992). However, individual uses cue in different buying situation for recalling the brand ad and greater chance of brand to be retrieved of any buyer, when different attributes are attached to the brand, which creates brand association (Romaniuk \& Sharp, 2004). As emotional advertising is considered most effective tools, so that consumer ultimately gives emotional response to that product (Brassington \& Pettitt, 2001). Normally, a positive relationship between visual, verbal and text intensity of media and emotional response has been found (Bezijian et al., 2008).

$\mathbf{H}_{\mathbf{1}}$ : There is a significant association between emotional response and consumer buying behavior in Pakistan.

Environmental Response: Environmental attitudes are defined by attitude theory, which is based on beliefs. Environmental attitude is based on those belief and norms, which are constructed through individual perception and this perception, should be taken as individual's opinion rather than an attitude (Heberlein \& Wisconsin, 1998). Environmental variables might affect on buying behaviors of consumer (Stern, 1962). As marketing related research proposed that environment provides certain type of experience for consumer, which are used for promotion and selling product or services (Adelaar et al., 2003). Specially, marketing research has conducted to describe the effect of different emotional condition at the time of purchasing (Morris \& Boone, 1998). The purchasers who cannot decide what to purchase, use the process of purchase intent (Goldsmith \& Lafferty, 2002). Purchase intent means customer purchase the product unintentionally and unplanned (Adelaar et al., 2003). Shopping lifestyle of consumer describes the behavior of consumer who wants to purchase and give positive responses towards the product (Tirmizi et al., 2009). In this condition consumer, take only information from retail store for purchase decision (Stern, 1962). However, the environmental psychology model provides better concept of emotional response rather than traditional marketing research (Hitchon, 1994). Sense modalities and information rates make the environmental psychology model. Sense modalities are sound, sight, and touch that can affect user experience. The information rate can affects user for gaining information from advertisement. So that in advertisement video, picture, and songs are strongly correlated. The environmental psychology model proposes an environment (such as retailing store) that produces an emotional feeling in an individual's mind, which is divided into pleasure, arousal or dominance in different buying situations (Adelaar et al., 2003).

$\mathbf{H}_{2}$ : There is an association between environmental response and consumer buying behavior in Pakistan.

In the light of above discussion, following research model is developed. Methodology, data collection and results will follow in the next sections.

\section{Methodology}

Sample and Procedure: The consumers who use different types of telecom services and who shop new services from their franchises, head office, in twin cities (Islamabad and Rawalpindi) of Pakistan were taken as the population of this study. A convenient sample (probability sampling method) was used. Total 200 questionnaires were distributed to consumers who filled the questionnaire on deliberately. When 50 questionnaires were filled then the reliability of the instrument was checked and the value of alpha was found 0.71. It is stated by Hair et al. (1998) the acceptance limit of reliability is 0.70 . The alpha value shows the positive reliability of instrument. After that further 150 responses were collected. Questionnaire was adopted from previous research and responses were collected within 45 days. Then SPSS version 16.0 was used for the analysis of these responses. This was a relational study so multiple regression was used.

Instrument: This instrument is based on two sub parts. Items were adapted from previous researches. The section one of the questionnaire contains the information about respondents i.e. age, gender, qualification and 
experience. This section was measure on nominal scale. The second section was about the research variables containing three variables one was dependent (consumer buying behavior) and two independent variables (emotional response and environmental response). The instrument was measured on 5 point likert scale rating strongly disagree to strongly agree, whereas, 1 was the least degree of agreement and 5 was the highest level of agreed and the variable emotional response (seven items) was taken from (Bijmolt, et al. 1998) and items of second variable environmental response (five items) was taken from the study of (Adelaar et al., 2003) and there were seven items of consumer buying behavior and the scale was taken from the study of (Dittmar et al., 2004).

Figure 1: Research Model

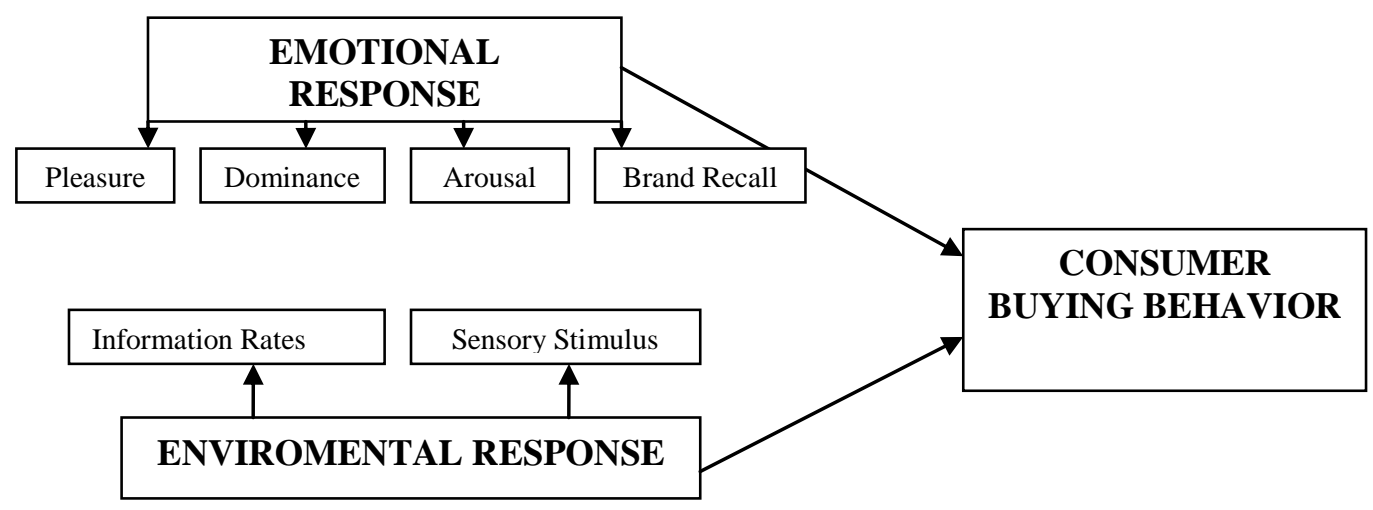

\section{Results and Discussion}

The data presented in the table 1 below shows the relationship of environmental response and emotiohal response with consumer buying behavior in Pakistan. The results show that hypothesis 1 is accepted and show positive relationship with dependent variable with $(\mathrm{p}<0.05)$. On the other hand, hypothesis 2 is rejected on its weak associations with $(\mathrm{p}>0.05)$.

Table 1: Beta Coefficients, Standard error in parenthesis, $t$-value in Brackets and p- values in italics)

\begin{tabular}{lllll}
\hline Constant & $\mathbf{I V}_{\mathbf{1}}$ & $\mathbf{I V}_{\mathbf{2}}$ & $\mathbf{R}^{\mathbf{2}}$ & F-Statistics \\
\hline 1.608 & .542 & .011 & .610 & 30.144 \\
$(.250)$ & $(.491)$ & $(.063)$ & & \\
{$[6.423]$} & {$[11.164]$} & {$[0.183]$} & & \\
.000 & .000 & & & .000 \\
Result of Hypothesis & $\mathrm{H}_{1}$ Accepted & $\mathrm{H}_{2}$ Rejected & - & - \\
\hline
\end{tabular}

Legend: Constant: Consumer buying behavior

$I V_{1}$ : Emotional response

$I V_{2}$ : Environmental response

The results show that independent variable; emotional response creates variation in the consumer buying behavior which is dependent variable with t-value [11.164] and it is significant at $(p<0.05)$, on the other hand $t$-values of environmental response creates no variation in the consumer buying behavior at $(p>0.05)$. The value of $F$ statistic is $(F=30.144)$ at $(p<0.05)$. The $R^{2}$ value is $(0.610)$ and $R(0.511)$ shows that these variables contribute 61 percent in this model. Goldsmith \& Lafferty (2002) proved positive association of emotional response with buying behavior of consumer. This study results are same that emotional response show positive relationship with consumer buying behavior. This shows that consumer only buy those products, which have emotional attachments. The result of (Adelaar et al., 2003) study shows positive 
relationship of environmental response and consumer buying behavior. However, in this study result are apposite that environmental response has no relationship with consumer buying behavior.

\section{Conclusion and Future Research}

The results of this study show that there is positive relationship of emotional response with consumer buying behavior and no relationship between environmental response and consumer buying behavior. Therefore, it is concluded that consumers purchase products by emotional response, rather that environmental response. In environmental response consumer do shopping unplanned but in this research consumer purchase those products from which consumer are emotionally attached. These attachments are created through advertisement as audio, video and text form, which appeals him or her. This research is conducted in telecom sector; therefore for generalization of these results, it is necessary for future researcher to empirically contribute to do this research by using other brands i.e. mobile advertising, FMCGS products automobiles, electronics etc. There should be novelty approach to attract the consumer buying behavior for future studies. Consumer buying behavior should be checked by consumer psychological behavior and social concerns. There is a need to conduct this research by personality trait of consumer, which creates impact on consumer buying behavior in Pakistan.

\section{References}

Adelaar, T., Chang, S., Lanchndorfer, K. M., Lee B. \& Morimoto M. (2003). Effects of Media Formats on Emotions \& Impulse Buying Behavior. Journal of Information Technology, 18, 247-266.

Ayanwale, A. B., Alimi, T. \& Ayanbimipe, M. A. (2005). The Influence of Advertising on Consumer Brand Preference. Journal of Social Science, 10(1), 9-16.

Bezijian, A. A., Calder, B. \& Iacobucci, D. (2008). New Media Interactive Advertising vs. Traditional advertising. Journal of Advertising Research, 38(4), 23-32.

Bijmolt, T. H. A., Claassen, W. \& Brus, B. (1998). Children are Understanding of TV Advertising: Effect of Age, Gender, and Parental Influence. Journal of Consumer Policy, 21, 171-194.

Bovee, L. C., Thill, V. J., Dovel, G. P. \& Wood, M. B. (1995). Advertising Excellence. McGraw Hill.

Brassington, F. \& Pettitt, S. (2001). Principles of Marketing, 3rd Edition, Pearson Education, Prentice Hall.

Dittmar, H., Long, K. \& Meek, R. (2004). Buying on the Internet: Gender Differences in On-line and Conventional Buying Motivations. Journal of Sex Roles, 50(5/6).

Goldsmith, R. E. \& Lafferty, B. A. (2002). Consumer response to websites \& their influence on advertising effectiveness. Internet research. Journal of Electronic Networking Application and Policy, 12(4), 318328.

Hair, J. F., Anderson, R. E., Tatham, R. L. \& Black, W. C. (1998). Multivariate Data Analysis, Fifth edition, Prentice-Hall International, Inc.

Heberlein, T. A. \& Wisconsin, M. (1998). Environnemental Attitudes. ZfU, (2)81, 241-270.

Hitchon, J. (1994). Effect of Ambiguity \& Complexity on Consumer Response to Music Video Commercials. Journal of Broadcasting \& Electronic Media, 38(3), 289-306.

Holden, S. J. S. \& Lutz, R. J. (1992). Ask Not What the Brand Can Evoke; Ask What Can Evoke the Brand. Journal of Advances in Consumer Research, 19, 101-107.

Hussainy, S. K., Riaz, K., Kazi, A. K. \& Herani, G. M. (2008). Advertising Styles Impact on Attention in Pakistan. KASBIT Business Journal, 1(1), 28-38.

Jalees, T. (2006). Brand Personification of Mobilink, U Phone, Telenor, and Warid. Journal of Research Market Forces, 2(2), 50-76.

Katke, K. (2007). The Impact of Television Advertising on Child Health \& Family Spending. International Marketing Conference on Marketing \& Society. Retrieved on Dated, 10-04-2009.

Keller, L. K. (2006). Strategic Brand Management Process, in Prespective of Modern Brand management, Ed. Dr. Franz-Rudolf Esch.

Mendelson, A. L. \& Bolls, P. D. (2002). Emotional effects of advertising on young adults of lower socio economicstatus. Retrieved on Dated: 01-05-2009.

Morris, J. D. \& Boone, M. A. (1998). The Effect of Music on Emotional Response, Brand Attitude, \& Purchase Intent in an Emotional Advertising Condition. Advances in Consumer Research, 25, 518-526. 
Romaniuk, J. \& Sharp, B. (2004). Conceptualizing \& Measuring Brand Salience. Marketing Theory Articles, 4(4), 327-342.

Smith, R. E. \& Swinyard W. R. (1983). Attitude- Behavior Consistency: The Impact of Product Trial versus Advertising. Journal of Marketing Research, 1, 257-267.

Stern, H. (1962). The Significance of Impulse Buying Today. Journal of Marketing, 26, 59-62.

Tirmizi, M. A., Rehman, K. U. \& Saif M. I. (2009). An Empirical Study of Consumer Impulse Buying Behavior in Local Markets European. Journal of Scientific Research, 28, 522-532. 